\title{
Emergency Department demand associated with seasonal influenza, 2010 through 2014, New South Wales, Australia
}

\author{
David J Muscatello, ${ }^{a}$ Kendall J Bein ${ }^{b}$ and Michael M Dinh ${ }^{b, c}$ \\ Correspondence to David Muscatello (email: david.muscatello@unsw.edu.au)
}

Introduction: Influenza's impact on health and health care is underestimated by influenza diagnoses recorded in healthcare databases. We aimed to estimate total and non-admitted influenza-attributable hospital Emergency Department (ED) demand in New South Wales (NSW), Australia.

Methods: We used generalized additive time series models to estimate the association between weekly counts of laboratory-confirmed influenza infections and weekly rates of total and non-admitted respiratory, infection, cardiovascular and all-cause ED visits in NSW, Australia for the period 2010 through 2014. Visit categories were based on the coded ED diagnosis or the free-text presenting problem if no diagnosis was recorded.

Results: The estimated all-age, annual influenza-attributable respiratory, infection, cardiovascular and all-cause visit rates/100 000 population/year were, respectively, 120.6 (99.9\% confidence interval [CI] 102.3 to 138.8), 79.7 (99.9\% Cl: 70.6 to 88.9$), 14.0$ (99.9\% Cl: 6.8 to 21.3 ) and 309.0 (99.9\% Cl: 208.0 to 410.1 ). Among respiratory visits, influenza-attributable rates were highest among $<5$-year-olds and $\geq 85$-year-olds. For infection and all-cause visits, rates were highest among children; cardiovascular rates did not vary significantly by age. Annual rates varied substantially by year and age group, and statistically significant associations were absent in several years or age groups. Of the respiratory visits, $73.4 \%$ did not require admission. The non-admitted proportion was higher for the other clinical categories. Around 1 in 100 total visits and more than 1 in 10 respiratory or infection visits were associated with influenza.

Discussion: Influenza is associated with a substantial and annually varying burden of hospital-attended illness in NSW.

nfluenza remains a public health challenge. ${ }^{1}$ It is associated with annual, varying, excess deaths in populations internationally. ${ }^{2,3}$ Influenza is a vaccinepreventable disease, ${ }^{1}$ and the extent of its contribution to morbidity and mortality is poorly recognized. Estimating the burden of influenza in various settings is thus a priority for the World Health Organization (WHO). ${ }^{4}$ There are few studies estimating the impact of influenza on lower severity health outcomes including hospital Emergency Department (ED) visits. ${ }^{5-8}$ There is increasing recognition that the impact of influenza extends beyond respiratory illness to circulatory and other diseases. ${ }^{2,9}$

Influenza-related illness is poorly recorded in hospital and death databases, and counting only laboratory-confirmed influenza infections will markedly underestimate influenza's population impact. Diagnoses commonly assigned to patients with an influenza infection in hospital EDs in Australia include fever, an unspecified infection or a non-respiratory illness. ${ }^{10}$ During influenza season, febrile convulsions in infants increase. ${ }^{11}$ Thus, statistical time-series analysis is used to estimate population levels of illness and death attributable to influenza. 2,10,12

We used time-series analysis to estimate the rate, number and proportion of ED visits attributable to influenza in the state of New South Wales (NSW), Australia by age and year for the period 2010 to 2014. Since a proportion of visits lead to admission and can be included in hospitalization estimates, we also prepared estimates for non-admitted visits. 


\section{METHODS}

\section{Study design and setting}

This was a retrospective, ecological time-series analysis of $E D$ visits recorded in a state-wide administrative information system database for NSW over the five calendar years of 2010 to 2014. NSW is the most populous state in Australia with a diverse urban and rural population of 7.5 million over $800000 \mathrm{~km}^{2} .^{13,14}$

\section{Data sources}

The available study data included all visits recorded in the NSW Emergency Department Data Collection database during the study period. ${ }^{15}$ The database contains routinely collected administrative and clinical data for patient-level visits across most public hospitals in NSW. Exclusion criteria were: hospitals not submitting data for the entire study period, prearranged (planned) visits that are usually for follow-up from a previous attendance, patients dead on arrival and transfers from other facilities. ${ }^{15}$ Population denominators were obtained from the Australian Bureau of Statistics. ${ }^{14}$

Prior to analysis, we assigned a single, mutually exclusive clinical category to each visit in the ED database. The category was assigned using the recorded primary ED diagnosis code, and if necessary, the presenting problem, as defined in a previous publication, which also includes examples of diagnoses in each category. ${ }^{15}$ For each ED visit, a physician selects a diagnosis name from a list used by the hospital's electronic patient medical record information system. The information system then assigns a diagnosis code depending on the diagnostic classification standard used by the hospital. Classification standards vary among the information systems and can be: the International Classification of Diseases versions 9 or 10 (ICD-9, ICD-10) or the Systematized Nomenclature of Medicine Clinical Terminology (SNOMED-CT).

To estimate the contribution of influenza to populationlevel health outcomes, a time series representing the relative weekly change in incidence of influenza infections in the population is needed as an independent variable in the regression analysis. Since all influenza infections diagnosed in microbiology laboratories in Australia are notifiable to regional and state health authorities, we used influenza notifications from NSW to prepare the time series. Non-identified, state-level notification data are available from the national health authority. ${ }^{16}$

\section{Outcomes}

We modelled outcome time series as population rates for each of respiratory, infection, cardiovascular and all-cause (total) visits. The association between influenza infection and adverse cardiovascular outcomes is becoming well known and is often included in influenza-attributable mortality studies. ${ }^{9}$ All-cause visits cast the widest net to estimate total influenza-attributable outcomes in timeseries approaches to influenza burden estimation. ${ }^{2}$

Time series of the total and non-admitted ED outcome rates were prepared for persons of all ages as well as age groups broadly consistent with WHO guidelines for influenza burden estimation: 0-4, 5-14, $15-49,50-64,65-84$ and $\geq 85$ years. $^{4}$

\section{Analysis}

We used semi-parametric generalized additive modelling to regress the ED outcome against the influenza time series. For each clinical category, age and admission status group, the weekly rates of ED visits provided the dependent (outcome) variable for a time-series model. Each time series included 260 observations covering whole weeks occurring during the study period.

Weekly influenza notification counts were split into separate variables for each year as there is an evident increase in influenza testing and thus notifications over time. ${ }^{2,17}$ Each annual influenza time series was set to zero in all years except the year to which it referred.

Much of the variation in the observed time series of ED visits is not due to influenza and much of that variation may be due to seasonal and other nonlinear factors. Therefore, a natural cubic smoothing spline of time (represented by consecutive week number) was included in the model as a non-parametric independent variable. $^{12}$ 
For a given clinical category, age group and admission status group, the model equation was:

$$
\begin{aligned}
& \text { Expected }(\text { visit rate })= \\
& \beta_{0}+\beta_{1}(\text { ChristmasNewYear })+\beta_{2}(\text { SchoolHoliday }) \\
& +\beta_{3}(\text { Easter })+\beta_{4}(\text { JanuaryWeek } 2) \\
& +\left[\sum_{\text {year }=2010}^{2014} \beta_{5, \text { year }}\left(\text { influenza }_{\text {year }}\right)\right] \\
& +\beta_{6} t+\text { spline }(t)
\end{aligned}
$$

in which "Christmas", "New Year", "School Holiday", "Easter" and "January Week 2" were holiday indicator variables (value 0 or 1 ) for periods of low ED demand, identified using a box whisker plot of the distribution of week of the year counts of all-cause visits. The influenza $a_{\text {year }}$ variable was the respective annual weekly time series of seasonal influenza notifications. The $\beta$ values were the model parameter estimates for the respective parametric independent variables, with $\beta_{0}$ the model intercept. We specified 31 degrees of freedom for the flexibility of the smoothing spline based on previous research. ${ }^{12}$

The estimated weekly component of visits associated with the influenza variable was obtained by multiplying the influenza parameter estimate $\left(\beta_{5, \text { year }}\right)$ by the observed rate of the influenza variable (influenza $a_{\text {year }}$ ) in each week. Annual total counts were converted to rates using mid-year population estimates.

Estimated influenza-attributable counts and total counts, respectively, were used as the numerator and denominator for influenza-attributable proportions in each outcome category and age group.

Since estimates were made for numerous year, age group and visit category combinations, $99.9 \%$ confidence intervals ( $\alpha=0.001$ ) were calculated to reduce chance statistical significance. We used the formula: parameter estimate $\pm 3.290 \times$ standard error of the parameter estimate where 3.290 is the $99.9 \%$ critical value (z-value) from a standard normal distribution. Standard errors for confidence intervals of five-year averages were the square root of the sum of the squared standard errors of the annual values divided by five (the number of years averaged). Non-statistically significant annual values were included in averages as zero with zero standard error.

SAS version 9.4 (SAS, Cary, NC, USA) was used for analysis using procedures and options described elsewhere. ${ }^{12}$ Normally distributed model residuals was assumed and this was checked using quantile-quantile (QQ) plots of the residuals. Lack of serial independence (autocorrelation) over time in the model residuals was checked using autocorrelation plots.

\section{Sensitivity analysis}

As a sensitivity analysis to assess whether influenza incidence was associated with visit categories that would implausibly be caused by influenza, injury visit rates were also regressed on the influenza notification time series.

\section{Ethics}

The study was approved by the NSW Population and Health Services Research Ethics Committee. Information that could identify patients was not included in the study data.

\section{RESULTS}

\section{Characteristics of the study data used}

There were 11.8 million ED visits recorded between January 2010 and December 2014 of which 10.8 million visits to 115 hospitals met the inclusion criteria. Of these, 7.82 million (72.8\%) were not admitted.

Among the clinical categories included in the study, injury comprised the largest group (mean $=117$ visits/100 000 population/week) followed by respiratory (49.0 visits/100 000 population/week), cardiovascular (44.2 visits/100 000 population/week) and infection (22.9 visits/100 000 population/week). Among nonadmitted visits, a similar pattern was observed. Increased influenza testing over time was evident; of the 44308 influenza notifications during the study period, almost one half (20 744, 46.8\%) occurred in 2014.

\section{Model fitting}

Except for cardiovascular disease visits in the older population, at least one statistically significant holiday effect was identified in each clinical category and age group. Apart from some departures from normality for extreme observations and some residual autocorrelation, the $\mathrm{QQ}$ plots showed the modelling provided a good fit to the observed data. 


\section{Main results}

Exceedances in visit rates associated with circulating influenza are evident in each clinical category, particularly respiratory and infection. The exceedances are most distinct in years 2012, 2013 and 2014 (Fig. 1).

For respiratory visits, exceedances were greatest in 2012 in < 5-year-olds (939.0 visits [99.9\% confidence interval (Cl) 559.4 to 1318.7$] / 100000$ population/ year) and $\geq 85$-year-olds (987.7 [99.9\% Cl: 793.4 to 1181.9]/100 000 population/year) (Fig. S1, Table S1, Supplementary File 1). For infection visits, exceedances were most prominent in < 5-year-olds in 2012 (821.6 visits [99.9\% Cl: 657.8 to 985.4$] / 100000$ population/ year) (Fig. S2, Table S1). Exceedances among cardiovascular visits were more difficult to distinguish and were most evident in $\geq 85$-year-olds in 2011 (433.0 [99.9\% Cl: 179.8 to 686.3$] / 100000$ population/year) (Fig. S3, Table S1). Among all-cause visits, 2012 again stood out in < 5-year-olds (2368.0 [99.9\% Cl: 1544.1 to $3191.8 \mathrm{~d} / 100000$ population/year) and $\geq 85$-yearolds (1778.4 [99.9\% Cl: 1060.0 to 2496.9$] / 100000$ population/year) (Fig. S1, Table S1).

When averaged from 2010 through 2014, there was a U-shaped relationship between age and estimated respiratory visit rates with $<5$-year-olds and $\geq 65$-yearolds higher than 15-64-year-olds based on confidence intervals. Compared with other age groups, estimated infection visit rates were highest in $<5$-year-olds, followed by $5-14$-year-olds, and these differences were statistically significant. The estimated infection visit rate in $<5$-yearolds was significantly higher than the estimated respiratory rate in the same age group. For cardiovascular visits, significant rates were present only in the 5-14, 15-49 and 65-84 age groups, and these were not significantly different across those age groups. Estimated all-cause rates were highest in $<5$-year-olds and declined with age until the 50-64 year age group and then increased again with the rate in $\geq 85$-year-olds about half that of $<5$-year-olds (Table 1 ).

Among persons of all ages, the average annual estimated influenza-attributable rate for respiratory visits was 120.6 [99.9\% Cl: 102.3 to 138.8$] / 100000$ population/year $(8887$ [99.9\% Cl: 7548 to 10 227] visits/year). For infection visits, the rate was 79.7
[99.9\% Cl: 70.6 to 88.9$] / 100000$ population/year (5856 [99.9\% Cl: 5192 to 6519] visits/year). For cardiovascular visits, the average was $14.0[99.9 \% \mathrm{Cl}$ : 6.8 to 2.3$] / 100000$ population/year $(1033[99.9 \% \mathrm{Cl}$ : 499 to 1567] visits/year). For all-cause visits, the allage average annual estimated rate was 309.0 [99.9\% Cl: 208.0 to 410.1$] / 100000$ population/year (22 619 [99.9\% Cl: 15268 to 29 969] visits/year) (Table 1).

In $<$ 50-year-olds, differences between the estimated rates in total and non-admitted visits are not significantly different. In older age groups, the rates of estimated non-admitted visits were substantially and significantly lower than those of total visits, particularly for the respiratory and infection categories. For persons of all ages, estimates for non-admitted visits were broadly similar to those of total visits. Averaged across all years, these patterns were also broadly reflected. These results indicate that older persons with influenza-related illness are more likely to be admitted (Tables S2 and S4, Supplementary File 1).

Compared with total visits (Table 1), a similar pattern of statistically significant associations was evident among non-admitted visits. The average annual estimated all-age rate of influenza-attributable, nonadmitted respiratory visits was $88.5(99.9 \% \mathrm{Cl}: 74.7$ to 102.3$) / 100000$ population/year or $73.4 \%$ of total influenza-attributable respiratory visits/year). For nonadmitted infection visits, the rate was $69.8(99.9 \% \mathrm{Cl}$ : 61.9 to 77.7$) / 100000$ population/year (87.4\%). For nonadmitted cardiovascular visits, the rate was 12.2 (99.9\% Cl: 7.9 to 16.5$) / 100000$ population/year (87.1\%). The rate of excess average annual all-cause non-admitted visits was $287.1(99.9 \% \mathrm{Cl}: 196.2$ to 378.0$) / 100000$ population/year; 92.8\%) (Table 2).

An annual average of $4.7 \%$ of total respiratory visits and $5.6 \%$ of non-admitted respiratory visits was estimated to be attributable to influenza. Among infection visits, the average annual proportion was $6.7 \%$ (non-admitted: $8.4 \%$ ). Among cardiovascular and all-cause visits, the average annual proportions were $0.6 \%$ (non-admitted: $1.1 \%$ ) and $1.1 \%$ (non-admitted: $1.3 \%$ ), respectively. The highest proportion by age was $12.4 \%$ (non-admitted: $13.6 \%$ ) of infection visits in 5-14-year-olds (Table S5, Supplementary File 1). 
Fig. 1. Observed weekly counts of influenza notifications, estimated influenza-attributable and non-influenzaattributable (background) ED visit rates/100 000 population/week for all-cause, cardiovascular, infection and respiratory clinical categories and observed visit rates/100 000 population/week in each clinical category, for persons of all ages, NSW, 2010 through 2014 ( $n=260$ weeks)
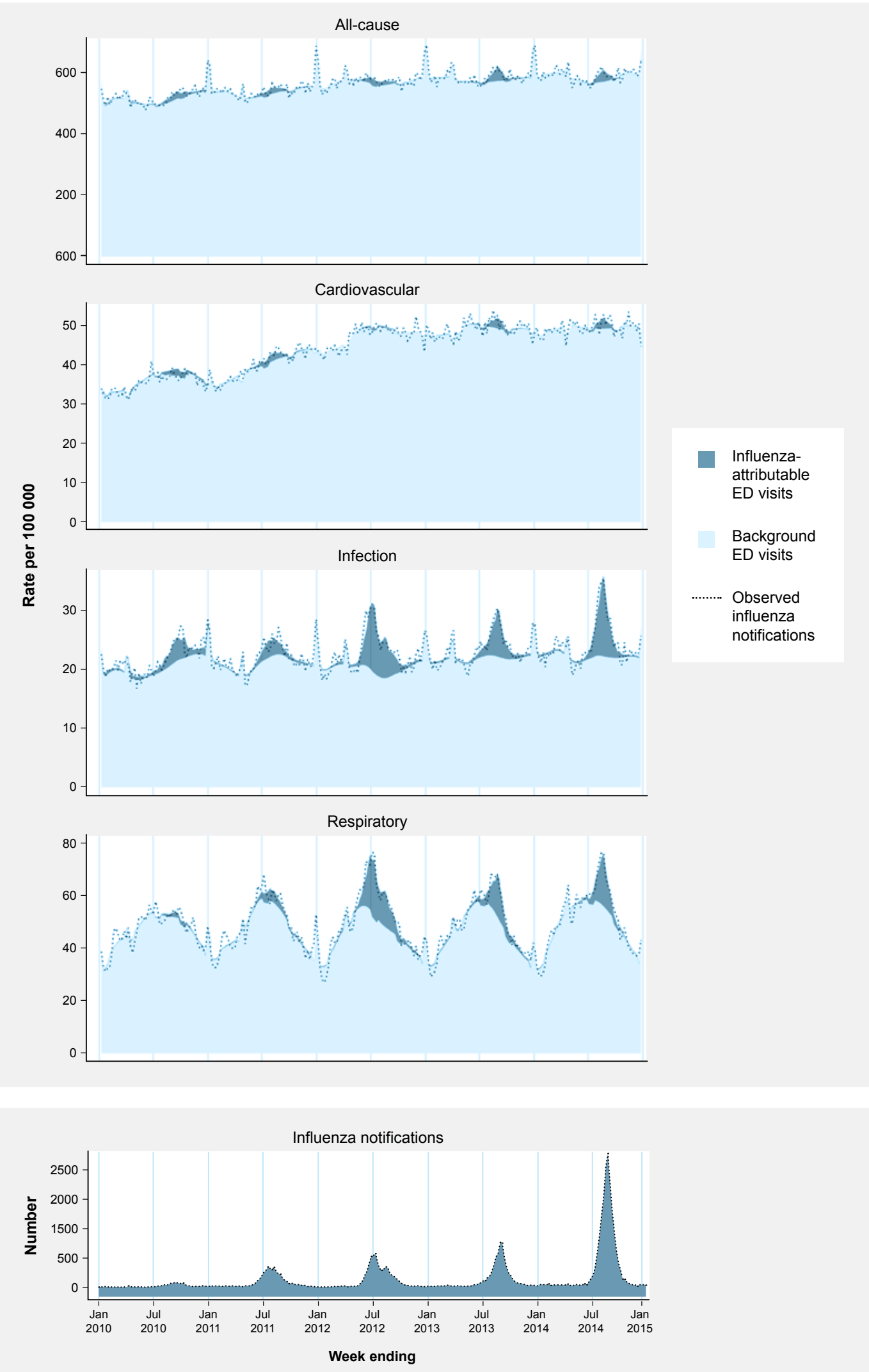
Table 1. Average annual estimated rate/100 000 population and number of influenza-attributable ED visits, by clinical category and age, NSW, 2010 through 2014

\begin{tabular}{|c|c|c|c|c|c|}
\hline Clinical category & Age group (years) & Rate & $(99.9 \% \mathrm{Cl})$ & Number & $(99.9 \% \mathrm{Cl})$ \\
\hline \multirow[t]{7}{*}{ Respiratory } & $0-4$ & 187.8 & (111.9 to 263.7 ) & 902 & (537 to 1266) \\
\hline & $5-14$ & 106.9 & (71.2 to 142.6$)$ & 976 & (651 to 1301) \\
\hline & $15-49$ & 80.7 & (72.6 to 88.9 ) & 2845 & (2558 to 3132 ) \\
\hline & $50-64$ & 95.0 & (80.7 to 109.3 ) & 1275 & (1085 to 1465$)$ \\
\hline & $65-84$ & 178.6 & (160.1 to 197.1$)$ & 1724 & (1544 to 1903) \\
\hline & $\geq 85$ & 208.6 & (115.1 to 302.0$)$ & 335 & (200 to 470$)$ \\
\hline & All ages & 120.6 & (102.3 to 138.8 ) & 8887 & (7548 to 10227 ) \\
\hline \multirow[t]{7}{*}{ Infection } & $0-4$ & 361.0 & (291.2 to 430.8$)$ & 1740 & (1405 to 2076) \\
\hline & $5-14$ & 144.1 & (123.3 to 165.0$)$ & 1304 & (1117 to 1492 ) \\
\hline & $15-49$ & 57.9 & (51.2 to 64.6 ) & 2035 & (1800 to 2269 ) \\
\hline & $50-64$ & 24.8 & (20.1 to 29.6 ) & 336 & (272 to 401 ) \\
\hline & $65-84$ & 25.6 & (19.7 to 31.6$)$ & 248 & (191 to 305 ) \\
\hline & $\geq 85$ & 45.5 & (25.2 to 65.8$)$ & 68 & (38 to 99 ) \\
\hline & All ages & 79.7 & (70.6 to 88.9 ) & 5856 & (5192 to 6519 ) \\
\hline \multirow[t]{7}{*}{ Cardiovascular } & $0-4$ & -3.4 & $(-5.8$ to -0.9$)$ & -16 & $(-28$ to -4$)$ \\
\hline & $5-14$ & 6.3 & (2.8 to 9.7 ) & 57 & (26 to 89 ) \\
\hline & $15-49$ & 5.7 & (1.9 to 9.6$)$ & 203 & (67 to 339 ) \\
\hline & $50-64$ & 0.0 & $(0.0$ to 0.0$)$ & 0 & $(0$ to 0$)$ \\
\hline & $65-84$ & 16.7 & $(0.2$ to 33.2$)$ & 152 & ( 2 to 301$)$ \\
\hline & $\geq 85$ & 17.0 & $(-63.3$ to 97.3$)$ & 28 & $(-82$ to 138$)$ \\
\hline & All ages & 14.0 & (6.8 to 21.3 ) & 1033 & (499 to 1567 ) \\
\hline \multirow[t]{7}{*}{ All-cause } & $0-4$ & 1013.9 & (692.1 to 1335.8 ) & 4856 & (3315 to 6397) \\
\hline & $5-14$ & 455.5 & (311.7 to 599.3) & 4115 & (2820 to 5410$)$ \\
\hline & $15-49$ & 175.3 & (102.8 to 247.7 ) & 6174 & (3625 to 8724 ) \\
\hline & $50-64$ & 49.3 & (15.7 to 82.9$)$ & 668 & (213 to 1123 ) \\
\hline & $65-84$ & 194.3 & (125.0 to 263.6 ) & 1870 & (1199 to 2540 ) \\
\hline & $\geq 85$ & 506.9 & (318.4 to 695.5) & 761 & (475 to 1047 ) \\
\hline & All ages & 309.0 & (208.0 to 410.1 ) & 22619 & (15 268 to 29969 ) \\
\hline
\end{tabular}

Notes: Non-statistically significant annual values were included in averages as zero, with zero standard error. $\mathrm{Cl}=$ confidence interval. Statistically significant positive results are shown in bold. Statistically significant negative results are italicized. 
Table 2. Average annual estimated rate/100 000 population and number of influenza-attributable non-admitted ED visits, by clinical category and age, NSW, 2010 through 2014

\begin{tabular}{|c|c|c|c|c|c|}
\hline Clinical category & Age group (years) & Rate & $(99.9 \% \mathrm{Cl})$ & Number & $(99.9 \% \mathrm{CI})$ \\
\hline \multirow[t]{7}{*}{ Respiratory } & $0-4$ & 276.8 & (185.9 to 367.8 ) & 1337 & (896 to 1778 ) \\
\hline & $5-14$ & 142.7 & (106.5 to 179.0$)$ & 1295 & (968 to 1621 ) \\
\hline & $15-49$ & 69.0 & (61.9 to 76.2 ) & 2432 & (2182 to 2682 ) \\
\hline & $50-64$ & 54.2 & (44.9 to 63.4 ) & 727 & (605 to 850$)$ \\
\hline & $65-84$ & 70.6 & (59.9 to 81.4 ) & 682 & (578 to 787 ) \\
\hline & $\geq 85$ & 30.6 & (2.4 to 58.8 ) & 49 & (8 to 91 ) \\
\hline & All ages & 88.5 & (74.7 to 102.3 ) & 6525 & (5511 to 7538 ) \\
\hline \multirow[t]{7}{*}{ Infection } & $0-4$ & 319.5 & (258.2 to 380.7$)$ & 1539 & (1245 to 1833 ) \\
\hline & $5-14$ & 131.6 & (112.8 to 150.5$)$ & 1191 & (1021 to 1361 ) \\
\hline & $15-49$ & 53.3 & (47.7 to 59.0 ) & 1875 & (1677 to 2073) \\
\hline & $50-64$ & 18.5 & (14.9 to 22.2 ) & 251 & (202 to 300$)$ \\
\hline & $65-84$ & 11.9 & (7.1 to 16.6$)$ & 113 & (69 to 158 ) \\
\hline & $\geq 85$ & -15.3 & $(-22.8$ to -7.7$)$ & -22 & $(-32$ to -11$)$ \\
\hline & All ages & 69.8 & (61.9 to 77.7 ) & 5121 & (4547 to 5694 ) \\
\hline \multirow[t]{7}{*}{ Cardiovascular } & $0-4$ & -2.2 & $(-4.2$ to -0.2$)$ & -11 & $(-21$ to -1$)$ \\
\hline & $5-14$ & 5.8 & (2.7 to 8.9 ) & 53 & (25 to 82 ) \\
\hline & $15-49$ & 9.3 & (5.4 to 13.2$)$ & 329 & (191 to 467 ) \\
\hline & $50-64$ & 5.6 & (1.3 to 9.9$)$ & 77 & (17 to 136$)$ \\
\hline & $65-84$ & 12.8 & (4.2 to 21.4 ) & 116 & (38 to 194 ) \\
\hline & $\geq 85$ & 22.0 & $(-6.2$ to 50.3$)$ & 30 & $(-11$ to 70$)$ \\
\hline & All ages & 12.2 & (7.9 to 16.5 ) & 900 & (586 to 1214 ) \\
\hline \multirow[t]{7}{*}{ All-cause } & $0-4$ & 1090.0 & (787.1 to 1392.8 ) & 5235 & (3780 to 6690$)$ \\
\hline & $5-14$ & 432.0 & (301.3 to 562.7 ) & 3903 & (2726 to 5080 ) \\
\hline & $15-49$ & 174.2 & (109.7 to 238.8 ) & 6141 & (3869 to 8413 ) \\
\hline & $50-64$ & 89.4 & (37.5 to 141.3 ) & 1177 & (497 to 1857 ) \\
\hline & $65-84$ & 122.3 & (52.1 to 192.4 ) & 1106 & (473 to 1739 ) \\
\hline & $\geq 85$ & -93.9 & $(-178.7$ to -9.1$)$ & -132 & $(-252$ to -13$)$ \\
\hline & All ages & 287.1 & (196.2 to 378.0$)$ & 20997 & (14 383 to 27611$)$ \\
\hline
\end{tabular}

Notes: Non-statistically significant annual values were included in averages as zero, with zero standard error. $\mathrm{Cl}=$ confidence interval. Statistically significant positive results are shown in bold. Statistically significant negative results are italicised. 


\section{Sensitivity analysis}

When injury visit rates were regressed on influenza incidence, a positive statistically significant association was identified for one age group in one year (5-14 yearolds in 2013; 208.5 (99.9\% Cl: 44.9 to 372.2$) / 100000$ population/year). Statistically significant negative results were identified for six of seven age groups in 2012 and three of seven age groups in 2014 (Table S6, Supplementary File 1). The overall proportion of estimated influenzaattributable injury visits was $-0.6 \%$.

\section{DISCUSSION}

We estimated that influenza was associated with approximately 1 in every 100 ED visits and more than 1 in 10 respiratory or infection visits, on average, concentrated across mid-winter to early spring. Over 300 all-cause visits/100 000 population/year were associated with influenza. Of these, 121 and 80/100 000 population/year were respiratory and infection visits, respectively. Influenza possibly explained 14 cardiovascular visits/100 000 population/year, although age groups and years with significant associations did not appear comparable with those for respiratory and infection visits. Depending on the type of visit, the burden appears to be borne to the greatest degree by the youngest and oldest age groups. Over 1000 all-cause visits/100 000 population/year in children aged under 5 years were associated with influenza and over 400/100 000 population/year in $\geq 85$ year-olds. Approximately three quarters of influenza-attributable respiratory visits did not require admission, compared with $87 \%$ for infection visits and $93 \%$ of all-cause visits. Young children were less likely than older adults to be admitted to hospital.

Our post-pandemic, influenza-attributable, annual respiratory visit rate estimate of $121 / 100000$ population/ year for the period 2010-2014 in NSW was substantially lower than estimates from Ontario, Canada and New York, NY, USA at different time periods. ${ }^{5,8}$ Varying influenza activity and virulence over time, immunization coverage and effectiveness, availability and cost of health services or different modelling approaches could explain the difference. The post-pandemic year in our study, namely 2010, did have unusually low influenza activity, and our modelling approach may provide more conservative estimates than the modelling method used in the other studies. $^{12}$
Interpreting variation in influenza-attributable burden from year to year requires an understanding of the influenza strains that circulated and the effectiveness of influenza vaccines. In Australia, influenza vaccination is free to certain risk groups, the largest group being the older population, with coverage around $70 \%$ in $\geq 65$-year-olds during the study period. ${ }^{18}$ Coverage in younger persons is substantially lower: around 33\% in 50-64-year-olds and below $20 \%$ in younger age groups. ${ }^{19}$

The 2009 influenza $A(H 1 N 1) p d m 09$ pandemic strain dominated in Australia in 2010, although levels of circulation were low (Table S7, Supplementary File 1). This is consistent with the low levels of influenzaattributable ED demand, although there was substantial demand in the younger age groups, particularly in the infection clinical category.

Influenza $A(H 3 N 2)$ reappeared in 2011 and cocirculated with the pandemic strain, but overall levels remained relatively low (Table S7). The vaccine in those years showed good effectiveness of at least $70 \%$ against the pandemic strain. ${ }^{20,21}$ The older age group experienced relatively low susceptibility to the pandemic strain due to pre-existing immunity. 2,12,19,22,23 These combined factors would explain the relatively low overall levels of influenza-attributable visits in 2010-2011.

The 2012 season showed the highest relative influenza circulation of the study period with $A(H 3 N 2)$ dominating and influenza $B$ accounting for the remainder (Table S7). This season had the highest estimated incidence of respiratory or infection ED visits of all years studied in persons of all ages and in $<5$-year-olds. The rates in $\geq 65$-year-olds were also highest in 2012 for respiratory, infection and all-cause visits. Vaccine effectiveness in Australia against the circulating H3N2 strain in that season was low at $30 \%$ in 2012 , which may be due to antigenic drift in the H3N2 virus. Effectiveness against influenza B was moderate (56\%). ${ }^{24}$

There was relatively low overall influenza circulation in 2013. Influenza A(H3N2) continued to dominate (Table S7). Substantial estimated influenza-attributable visits were evident in younger age groups broadly comparable to surrounding years. Vaccine effectiveness against $A(H 3 N 2)$ in 2013 was good at $67 \%,{ }^{24}$ which may explain the relatively lower levels of influenza-attributable visit rates in older age groups compared with the surrounding years. 
In 2014, the pandemic strain dominated but A(H3N2) co-circulated. This year had the second highest total apparent influenza circulation of the years studied (Table S7). In that year, the vaccine effectiveness was moderate $(55 \%)$ against pandemic $A(\mathrm{H} 1 \mathrm{~N} 1)$ but low (26\%) against $A(H 3 N 2),{ }^{24}$ possibly explaining substantial influenza-attributable rates in the older population.

The study had limitations. In NSW, the ED diagnosis is recorded as part of the routine workflow of physicians and not by health information managers trained in health care classification. Changes in information systems over time may have led to inconsistencies in the recording of diagnoses and other information. Diagnosis classifications varied across hospitals. ${ }^{15}$ We did not have information on other viruses, such as respiratory syncytial virus, which may have caused some residual confounding. Biases can arise in the influenza notifications we used because the decision to test for influenza is at the discretion of the health-care provider and notifications arise from any type of medical service. On the other hand, notifications provide a combination of wide geographic coverage and are very specific to influenza.

Of the 186 EDs in NSW, 19\% did not report to the Emergency Department Data Collection database during the study period and another $3 \%$ were excluded. Therefore, our results will be an underestimate of state-wide figures. Non-participating and excluded hospitals were smaller regional hospitals in more remote areas. ${ }^{15}$ Nevertheless, the data set we analysed included approximately $87 \%$ of public hospital visits in the state. ${ }^{25}$ ED services in NSW are almost wholly public. ${ }^{26,27}$

The statistically significant associations with injury are challenging to explain. The positive association may have been a chance finding even though we set a restrictive level of statistical significance. Unmeasured confounding could have occurred due, for example, to weather or other factors that vary on a similar time scale to influenza seasons. Confinement at home due to influenza may lead to fewer opportunities for injury, although this needs further study.

Using all-age rather than age-specific influenza notifications in the model might explain negative influenza-attributable estimates, which are, in reality, impossible. Using age-specific notifications in the model may improve estimates, but this requires further research.
In summary, seasonal influenza is associated with a substantial but annually varying burden of hospitalattended illness on EDs in NSW and thus on the overall population. The greatest demand occurs among young children and in the oldest population in some years. Varying vaccine effectiveness may have explained varying impact in the relatively well immunised older population. Improved vaccines and vaccination strategies that protect young children as well as older adults are needed to reduce morbidity in the population. Influenza surveillance information may be useful in forecasting and managing peaks in ED demand and to facilitate improved workload, staff and bed management. Improved control of influenza may substantially reduce surges in ED demand caused by influenza.

\section{Conflict of interest}

All authors report no conflicts of interest relevant to this article.

\section{Funding}

This project was funded by the NSW Agency for Clinical Innovation Award and the NSW Emergency Care Institute (reference number ACl/D14/2288).

\section{Acknowledgements}

We acknowledge the NSW Ministry of Health and the Centre for Health Record Linkage for access to, and linkage of, data.

\section{References}

1. Nicholson KG, Wood JM, Zambon M. Influenza. Lancet. 2003 Nov 22;362(9397):1733-45. pmid:14643124 doi:10.1016/ S0140-6736(03)14854-4

2. Simonsen L, Spreeuwenberg P, Lustig R, Taylor RJ, Fleming DM, Kroneman M, et al.; GLaMOR Collaborating Teams. Global mortality estimates for the 2009 Influenza Pandemic from the GLaMOR project: a modeling study. PLoS Med. 2013 Nov;10(11):e1001558. pmid:24302890 doi:10.1371/journal.pmed.1001558

3. Cheng P-Y, Palekar R, Azziz-Baumgartner E, luliano D, Alencar AP, Bresee J, et al. Burden of influenza-associated deaths in the Americas, 2002-2008. Influenza Other Respi Viruses. 2015 Aug;9 Suppl 1:13-21. pmid:26256291 doi:10.1111/irv.12317

4. A manual for estimating disease burden associated with seasonal influenza. Geneva: World Health Organization; 2016 (http://www. who.int/influenza/resources/publications/manual burden of disease/en/, accessed 15 April 2017).

5. Schanzer DL, Schwartz B. Impact of seasonal and pandemic influenza on emergency department visits, 2003-2010, Ontario, Canada. Acad Emerg Med. 2013 Apr;20(4):388-97. pmid:23701347 doi:10.1111/acem.12111 
6. Self WH, Griffin MR, Zhu Y, Dupont WD, Barrett TW, Grijalva CG. The high burden of pneumonia on US emergency departments during the 2009 influenza pandemic. J Infect. 2014 Feb;68(2):15664. pmid:24140066 doi:10.1016/j.jinf.2013.10.005

7. Guo RN, Zheng $H Z$, Ou $C Q$, Huang $L Q$, Zhou $Y$, Zhang $X$, et al. Impact of influenza on outpatient visits, hospitalizations, and deaths by using a time series poisson generalized additive model. PLoS One. 201602 19;11(2):e0149468. pmid:26894876 doi:10.1371/journal.pone.0149468

8. Olson DR, Heffernan RT, Paladini M, Konty K, Weiss D, Mostashari $F$. Monitoring the impact of influenza by age: emergency department fever and respiratory complaint surveillance in New York City. PLoS Med. 2007 Aug;4(8):e247. pmid:17683196 doi:10.1371/journal.pmed.0040247

9. Maclntyre CR, Mahimbo A, Moa AM, Barnes M. Influenza vaccine as a coronary intervention for prevention of myocardial in farction. Heart. 2016 Dec 15;102(24):1953-6. pmid:27686519 doi:10.1136/heartjnl-2016-309983

10. Muscatello DJ, Amin J, Maclntyre CR, Newall AT, Rawlinson WD, Sintchenko $\mathrm{V}$, et al. Inaccurate ascertainment of morbidity and mortality due to influenza in administrative databases: a populationbased record linkage study. PLoS One. 201405 29;9(5):e98446. pmid:24875306 doi:10.1371/journal.pone.0098446

11. Polkinghorne BG, Muscatello DJ, Macintyre CR, Lawrence GL, Middleton PM, Torvaldsen S. Relationship between the population incidence of febrile convulsions in young children in Sydney, Australia and seasonal epidemics of influenza and respiratory syncytial virus, 2003-2010: a time series analysis. BMC Infect Dis. 201110 26;11(1):291. pmid:22029484 doi:10.1186/14712334-11-291

12. Muscatello DJ, Newall AT, Dwyer DE, Macintyre CR. Mortality attributable to seasonal and pandemic influenza, Australia, 2003 to 2009, using a novel time series smoothing approach. PLoS One. 201306 03;8(6):e64734. pmid:23755139 doi:10.1371/journal. pone. 0064734

13. Area of Australia - States and Territories. Canberra: Geoscience Australia; 2017 (http://www.ga.gov.au/scientific-topics/nationallocation-information/dimensions/area-of-australia-states-and-territories, accessed 25 August 2017).

14. 3101.0 - Australian Demographic Statistics, Mar 2016. Canberra: Australian Bureau of Statistics; 2016 (http://www.abs.gov.au/Ausstats/abs@.nsf/mf/3101.0, accessed 3 November 2016).

15. Dinh MM, Berendsen Russell S, Bein KJ, Chalkley D, Muscatello $\mathrm{D}$, Paoloni R, et al. Understanding drivers of Demand for Emergency Service Trends in Years 2010-2014 in New South Wales: An initial overview of the DESTINY project. Emerg Med Australas. 2016 Apr;28(2):179-86. pmid:26840615 doi:10.1111/17426723.12542
16. Influenza (laboratory confirmed) public dataset. Canberra: Australian Department of Health; 2017 (http://www9.health.gov.au/cda/ source/pub_influ.cfm, accessed 24 August 2017).

17. Kelly HA, Grant KA, Tay EL, Franklin L, Hurt AC. The significance of increased influenza notifications during spring and summer of 2010-11 in Australia. Influenza Other Respi Viruses. 2013 Nov;7(6):1136-41. pmid:23176174 doi:10.1111/irv.12057

18. HealthStats NSW - Influenza and pneumococcal immunisation. North Sydney: New South Wales Health; 2016 (http://www. healthstats.nsw.gov.au/, accessed 15 April 2017).

19. Muscatello DJ, Barr M, Thackway SV, Macintyre CR. Epidemiology of influenza-like illness during pandemic (H1N1) 2009, New South Wales, Australia. Emerg Infect Dis. 2011 Jul;17(7):1240-7. pmid:21762578 doi:10.3201/eid1707.101173

20. Kelly HA, Sullivan SG, Grant KA, Fielding JE. Moderate influenza vaccine effectiveness with variable effectiveness by match between circulating and vaccine strains in Australian adults aged 20-64 years, 2007-2011. Influenza Other Respi Viruses. 2013 Sep;7(5):729-37. pmid:23078073 doi:10.1111/irv.12018

21. Levy A, Sullivan SG, Tempone SS, Wong KLM, Regan AK, Dowse GK, et al. Influenza vaccine effectiveness estimates for Western Australia during a period of vaccine and virus strain stability, 2010 to 2012. Vaccine. 2014 Oct 29;32(47):6312-8. pmid:25223268 doi:10.1016/j.vaccine.2014.08.066

22. Hancock K, Veguilla V, Lu X, Zhong W, Butler EN, Sun H, et al. Cross-reactive antibody responses to the 2009 pandemic H1N1 influenza virus. N Engl J Med. 2009 Nov 12;361(20):1945-52. pmid:19745214 doi:10.1056/NEJMoa0906453

23. Muscatello DJ, Cretikos MA, Macintyre CR. All-cause mortality during first wave of pandemic (H1N1) 2009, New South Wales, Australia, 2009. Emerg Infect Dis. 2010 Sep;16(9):1396-402. pmid:20735923 doi:10.3201/eid1609.091723

24. Sullivan SG, Carville KS, Chilver M, Fielding JE, Grant KA, Kelly $\mathrm{H}$, et al. Pooled influenza vaccine effectiveness estimates for Australia, 2012-2014. Epidemiol Infect. 2016 Aug;144(11):2317-28. pmid:27125368 doi:10.1017/S0950268816000819

25. Annual Report - Annual Report 2014-15 NSW Health. North Sydney: New South Wales Health; 2016 (http://www.health.nsw.gov. au/annualreport/Pages/annualreport15.aspx, accessed 15 April 2017).

26. 4390.0 - Private Hospitals, Australia, 2014-15. Canberra: Australian Bureau of Statistics; 2016 (http://www.abs.gov.au, accessed 15 April 2017).

27. Emergency department care 2014-15: Australian hospital statistics. Canberra: Australian Institute of Health and Welfare; 2016 (http://www.aihw.gov.au/publication-detail/?id=60129553619, accessed 3 November 2016). 